\title{
AN ELEMENTARY-SCHOOL HEALTH PROJECT
}

\author{
W. A. KING
}

Columbia School, Seattle, Washington

The project here described was directed by the principal and teachers of the Columbia School, Seattle, Washington, for the purpose of improving the children's health habits. Furthermore, its influence was expected to reach throughout the community tributary to the school. In a word, the community attitude toward the vital question of health was to be improved.

An additional challenge came from a new course of study in hygiene. The keynote of this course is the formation of proper health habits.

The plan was to establish a health program for the entire school that should make a strong appeal to the pupils. Its duration was to be sufficiently long to induce practices that would tend to prevail. The method of the study will show that every teacher had an opportunity to extend her influence to the whole school. This involves a departure from the customary method which is worthy of note.

A series of health posters was planned as a framework for the undertaking. The posters were to be prepared by pupils of the different rooms in succession and exhibited on a prominent wall space near the entrance to the main hall. Each of the rooms was allotted a period of two weeks, the entire study extending from January 5 to June $\mathrm{I} 7$, 1921.

In addition to its own regular classroom work in hygiene, each room was permitted to develop a series of lessons which were to be presented in attractive form to the whole school.

The room having charge of the project for a given period changed its posters and other lessons at frequent intervals. The response each time was a group of eager children whose pride in fulfilment or embarrassment in failure revealed the hold which this project had upon them. 
From the beginning the pupils were charged with absolute responsibility for the success of their efforts.

The new course of study contains a hygiene questionnaire that afforded the means for a comparative study. Fifteen of its twentyfour questions are here given:

I. Do you sleep with bedroom window open?

2. Do you eat breakfast every day?

3. Do you drink coffee?

4. Do you drink tea?

5. Do you eat slowly and chew your food thoroughly?

6. Do you have a regular time every day to go to the toilet ?

7. Is there a bathtub in your home?

8. Do you have a toothbrush of your own?

9. Have you any bad teeth ?

Io. Have you ever been to a dentist ?

II. Do you have headaches often?

I2. Do your eyes hurt often?

I3. Can you read writing on the blackboard easily?

I4. Can you hear easily what the teacher says?

I5. Do you often take cold?

This questionnaire had been submitted to a few of the city schools during the last term of the preceding year. Columbia was one of those schools. It was again submitted during the first term of the year I920-2r. Our study covers the period from this time to the close of the year when it was used a third time.

All pupils from the fourth grade to the eighth grade answered the questionnaire. The teachers then tabulated the answers and filed the papers and tabulation sheets for reference.

At the close of the project, the teachers submitted detailed accounts of their methods of procedure. It seems advisable to report here enough to identify and explain the nature of the various contributions.

Room $7(V I I A)$ and Room 8 (VIII A).-These rooms opened the building project with an attractive series of posters. The plans were all worked out by the girls in their classes in industrial design. The boys prepared the lettering in mechanical-drawing classes; while committees in the academic rooms had the responsibility of furnishing verses and providing for the displays. About twenty specimens were made. A typical one, under the caption, 
"Breakfast," showed the right and wrong ways to start the day. The right way showed cuts of cereal, milk, bread, and fruit, with a smiling boy as the result; the wrong way featured coffee and doughnuts, with a cross, peevish boy as the consequence.

Such vital topics as foods best for children to eat, proper bathing habits, care of the teeth, sufficient hours of sleep, and the right kinds of exercise were included in the series.

Room II (VIA-VII B).-This room followed up a study of heights and weights that had been instituted in the fall. At that time, several children were found to be underweight. Three sets of posters were developed under the direction of as many committees.

The first committee presented the challenge: How tall are you? How old are you? How much do you weigh? Suitable illustrations accompanied the challenge. Charts giving normal weights for all ages and heights were displayed.

The second committee explained the relation of good foods to weight; while the third committee rounded out the study with illustrations for two posters: this is the right weigh; this is the wrong weigh.

Room 5 (VIB-VIA).-This group presented in rhyme, story, and picture the history of two imaginary characters, "Smiles" and "Grouchy." Reading, language, and drawing periods were used at intervals to work out the story, compose the rhymes, and prepare the posters. The room was divided into sections which were responsible for the five elements of the project. The two characters were shown at the ages of one year, five years, nine years, twelve years, and at high-school age. "Smiles" was blest with intelligent parental care during babyhood and formed right habits of living; while "Grouchy" suffered from neglect during his early years and yielded later to bad teeth, poor posture, and other ills. In high school he was unable to compete with "Smiles" in athletics and other activities.

Room $6(V A)$.- Room 6 centered its study about the following topics: care of the teeth, hair, hands, and nails; tea and coffee; and proper bedtime. Every pupil made a poster on each of the points mentioned. 
Chew-Chew, the health clown, had visited our school previously. One of the boys was chosen to represent him, and his attitude toward the tea and coffee drinkers was skilfully wrought into the posters which were put up for inspection and study.

Room $4(I V A)$. - Health habits in general and the habits of a well-rounded day constituted the twofold theme of Room 4.

To express the first idea, the boys and girls developed a large poster in the center of which was a five-pointed star. Each point directed attention toward one of the five rules: plenty of sleep, nourishing food, cleanliness, fresh air, exercise. Each rule was illustrated with appropriate pictures.

Three large posters served to present the second idea. They were entitled: "Begin the Day Right"; "Work and Play Make a Happy Day"; and "End the Day Right."

Room 3 (IIIA-IVB). - This group worked out its part in three divisions: (I) Sleep with windows open. (2) Get plenty of fresh air and exercise. (3) Work hard but play and rest, too.

A survey of the classes earlier had shown that some of the children were sleeping with closed windows and that several of them were not getting sufficient rest.

To convey the first lesson, two homes were represented at night time. The bedroom window in one was closed; while in the other it was open. The results the following morning were indicated by the pictures of the two boys who had been photographed by the teacher for this purpose. The dramatization involved stimulated interest.

Room 2 (IIIB-IIIA). - There were six units in the study executed by Room 2: (I) Teeth; (2) Milk; (3) Hands; (4) Sleep; (5) Work; (6) Play.

These pupils were accustomed to assuming considerable responsibility in connection with the sand table and other projects. For a period of several weeks the children assembled from their homes and from stores the materials to be used in their project. The teacher left every possible choice and judgment to the pupils.

Room Io (II A).-The contribution from Room to was in four parts: ( I) A series of admonitions from a band of brownies covering points of eating, sleeping, playing, cleanliness, etc.; (2) a health 
ladder; (3) a milk poster; (4) a poster on the teeth. The use of dental floss instead of toothpicks was presented in a most clever way.

Room $9(I B-I A)$. - Room 9 worked out a group of fundamental health habits and displayed them in series. The appeals in sentence form were developed in class discussions.

Room I (IB-IA).-These pupils offered a challenge to the whole school with such questions as: Do you drink milk at noon? Are you ready for school? Did you go to bed early? Did you play hard? Did you eat breakfast? Did you clean your teeth?

At the close of the term the teachers responded in writing to an inquiry submitted by the principal. The object was to secure information for evaluating the project, especially certain residual factors. The responses were copious and detailed. Significant portions are presented in order to disclose the teachers' observations on the study.

I. Do you believe the health project has influenced pupils in the formation of better health habits? All teachers answered, "Yes."

2. If so, how? Typical answers: (a) Made class conscious of personal cleanliness; $(b)$ many go to bed earlier; many are neater and cleaner: $(c)$ more drink milk. Fewer drink coffee. Sleeping hours are better; $(d)$ older pupils have been influenced most in the matter of healthful eating.

3. Have your pupils been genuinely interested in the work done by other pupils? All teachers answered, "Yes."

4. After your room participated, did your pupils lose interest? All teachers answered, "No."

5. In what ways did your pupils keep in touch with the project? Typical answers: (a) By class inspections; $(b)$ stopped in the hall to read them. Often came in from play to do so; $(c)$ pupils read the bulletins every day and always watched for new posters; (d) we visited the bulletin boards in a body every Monday.

6. Have you found it stimulating, during hygiene recitations, to refer to the work of other rooms on the project? All teachers answered, "Yes." 
7. What uses have you made of it by way of correlation? Typical answers: (a) Silent reading; (b) sight reading; (c) written language; $(d)$ sand-table illustrations; (e) oxygen experiment; $(f)$ letter-cutting; $(g)$ selecting reading materials for our posters; (h) booklets, constructions, and binding; ( $i$ ) figuring percentages for health records, weight graphs, etc.; $(j)$ arrangement of materials on posters.

8. What evidence have you that the project brought about a closer contact between home and school? Typical answers: (a) Not so many pancakes served for breakfast now; (b) mention of health habits by parents when visiting; $(c)$ pupils report mothers' interest in weight; $(d)$ a few parents have ceased drinking coffee; (e) many children for the first time began sleeping with windows open.

9. Has it caused any friction or antagonism in this connection? All teachers, except one, answered, "No." This one stated that a few parents contended that weak, hot coffee is better for a child than cold milk.

Io. Has the project injected the idea of school unity into the minds of the pupils? All teachers answered, "Yes."

II. Did the high standards set at the beginning influence the good work that has prevailed throughout? All teachers answered, "Yes."

I2. Please record your individual impressions of the project. Typical responses: (a) This project will have a lasting influence on many children. (b) It increased children's powers of discrimination, judgment, criticism, and appreciation. (c) It has aroused in the children a desire for health. (d) Several mothers have spoken to me about the help it has been to them. The fact that it has been a school project has awakened keen interest. (e) This project has been a big thing. It has accomplished a purpose which I think will be lasting. ( $f)$ The building project has stimulated attention to health habits far beyond the normal interest. (g) In the formation of good habits, constant effort is required. It seems to me we have been working on a sound principle.

The advantages of a campaign of the type described may be summarized as follows: 
A project of this kind helps to establish a vital contact between home and school. Each day is one of twenty-four hours. Emphasis on this point enables the school to occupy a real place in the home. Most parents appreciate sincere efforts on the part of the school to guide the child in this important phase of his life.

This is a wholesome method of promoting school unity. It is not difficult to organize the interests of elementary-school children about the big question of health. The boys and girls enthuse over the community aspects of the work and maintain just enough classroom spirit to provide the competition that should obtain.

The study covers a period sufficiently long to determine tendencies in the formation of habits that are extremely vital.

It prepares the way for a larger community survey into general health conditions. In a word, it puts the school in a position to perform a service of high order in promoting an intelligent campaign for better health.

A progressive corps of teachers may be expected to give hearty co-operation in a project of this kind. There is general improvement among the pupils in personal appearance. The children start the day's work in better condition. School unity is advanced. Naturally, these things combine to aid in achieving many other results the teachers hope to secure.

This project furnishes convincing testimony that the school must have the co-operation of the home if health teaching is to be thoroughly successful. The five hours at school create the stimulus. During the remaining nineteen hours, the influence of the home is more immediate. It is mainly responsible for the wholesome recreation the child should have. It selects and apportions the food the child eats. It controls the hours of sleep. 